\title{
UMA DISCUSSÃO DA EFICIÊNCIA NA LITERATURA DA EXTENSÃO RURAL: LIMITES E PROPOSIÇÔES CONCEITUAIS
}

\author{
Angelina Moreira Melo ${ }^{1}$
}

Daniel Calbino Pinheiro ${ }^{2}$

\begin{abstract}
RESUMO
O artigo de natureza teórico-empírico discute o conceito de eficiência nas atividades de extensão rural, com o intuito de compreender inicialmente como o tema tem sido tratado na literatura. Os procedimentos metodológicos adotados foram uma revisão bibliográfica em periódicos, dissertações e teses que discutiam a temática entre os anos de 1987 a 2015. Os resultados encontrados em 19 trabalhos apontam para uma discussão que perpassa majoritariamente por dimensões técnicas, associando a atividade extensionista na difusão de tecnologias e no aumento da produtividade. Neste ínterim, propõe-se apresentar nas considerações finais uma proposta de um construto teórico, que visa ampliar o conceito de eficiência, abordando a dimensão econômica como uma pequena parte no processo de formação metodológica da assistência, na qual outras dimensões também são fundamentais para o fortalecimento e desenvolvimento das atividades extensionistas, relativizando assim, seu suposto caráter neutro e a-histórico.
\end{abstract}

Palavras-chave: eficiência, extensão rural, literatura acadêmica.

\section{LAW OF TECHNICAL ASSISTANCE AND RURAL EXTENSION IN ALAGOAS- BRAZIL: CONTRIBUTIONS OR DISCONTINUITY?}

\begin{abstract}
The article of theoretical-empirical discusses the concept of efficiency in rural extension activities, with the intention of initially as the theme has been treated in the literature. The methodological procedures adopted for a bibliographic review in periodicals, dissertations and theses that discussed a theme between the years of 1987 to 2015. The results found in 18 papers point to a discussion that perpasses mainly by technical dimensions, associating the extensionist activity in the diffusion of Technologies and not increase productivity. In the meantime, it is proposed to present the final considerations of a proposal for a theoretical construct, which aims to broaden the concept of efficiency, approaching the economic dimension as a small part not methodological training process of assistance, in other dimensions are also fundamental for Strengthening And development of the extensive activities, thus relativizing his supposed neutral and a-historical character.
\end{abstract}

Keywords: academic literature, efficiency, rural extension.

${ }_{1}^{1}$ Graduanda em Engenharia Agronômica Local (UFSJ). E-mail: angelinamoreiramelo@hotmail.com

1 Graduado em Administração. Mestre em Administração. Doutor em Administração. Professor da Universidade Federal de São João del Rei-Campus Sete Lagoas (UFSJ). E-mail: dcalbino@ufsj.edu.br 


\section{INTRODUÇÃO}

As práticas de extensão rural no Brasil foram institucionalizadas há mais de 50 anos, com o intuito de promover a melhoria das condições de vida da população rural e de apoiar o processo de modernização da agricultura, inserindo-se nas estratégias voltadas à política de industrialização (BRASIL, 2007). Zuin et al. (2011) afirmam que historicamente foi ofertada ao Brasil uma extensão tecnicista, em que as estratégias de desenvolvimento e intervenção empregadas consideravam apenas os aspectos técnicos da produção, sem observar as perspectivas culturais, sociais e ambientais dos produtores rurais e suas famílias.

Em similaridade, Caporal e Costabeber (2004) enfatizam que apesar de mudanças no histórico das atividades de extensão, ainda perpetua uma lógica produtivista e econômica, reflexo das bases da modernização e tecnificação da produção rural. A discussão do conceito de eficiência toma uma relevância, fazendo parte da busca de sua funcionalidade pelos extensionistas em suas atividades de campo. A preocupação com a eficiência é algo presente no cotidiano do campo, haja vista que a difusão de tecnologias, almejando alcançar os resultados positivos, muitas vezes, torna o conceito de eficiência restrito apenas ao sucesso técnico/econômico das atividades de extensão.

Por outro lado, deve-se enfatizar que o conceito de eficiência é amplo e relativo, e muitas vezes descontextualizado do ponto de vista histórico. Para definir e conceituar a eficiência faz-se necessário compreender o que o extensionista entende por este termo e ao que esta variável está relacionada. Um exemplo, seria como classificar um trabalho extensionista como sendo eficiente? Trata-se do desenvolvimento tecnológico da propriedade rural? Aumento de sua produção e lucratividade? Tratar-se-ia da não utilização de produtos agroquímicos? Seria o desenvolvimento psicossocial da família rural ou o desenvolvimento dos laços solidários entre os envolvidos? Através destas questões, pode-se perceber o quão relativo se torna o conceito de eficiência e o quanto ele depende do tipo de formação e influência a que o extensionista esteve exposto, bem como da pluralidade de objetivos dos produtores rurais.

Neste sentido o presente artigo de natureza teórico-empírico tem por objetivo central aferir junto à literatura como o seu conceito tem sido utilizado e aplicado nas práticas de extensão? Para tanto, a parte metodológica se recorrerá à investigação por dissertações/teses e periódicos, utilizando palavras-chaves que se associam ao tema, entre o período de 1987 a 2015. Após a apresentação dos dados, propõe-se nas considerações finais esboçar um construto teórico sobre eficiência para as atividades de extensão rural, relativizando assim sua aplicação as atividades extensionistas, e ampliando a discussão para a área ao trazer outras dimensões que não se limitam apenas aos aspectos técnicos e econômicos. 


\section{O CONCEITO DE EFICIÊNCIA NA VISÃO TRADICIONAL}

De um modo geral, o conceito de eficiência costuma ser tomado como consensual e em geral é descontextualizado do ponto de vista histórico. Contudo, para definir a eficiência faz-se necessário conceituá-la com relação a algo, o que indica o quão relativo é o tema. Parra (2002), Calbino e Paes de Paula (2014) afirmam que a noção de eficiência se instituiu como dominante e neutra (ausente de conflitos e disputas políticas), sendo definida como a capacidade de obter a melhor relação entre custos e benefícios (reais ou simbólicos, presentes ou potenciais) na forma de lucro (em termos da taxa de rentabilidade do capital). No entanto, os autores ressaltam que mesmo as organizações tradicionais são permeadas por diferentes racionalidades socioeconômicas, que não são nem monolíticas, nem unidirecionais. Estas racionalidades são portadoras de contradições que as tornam multidimensionais (sujeita a vários critérios) e determinadas historicamente (variam no tempo, no espaço e de acordo com a configuração do campo econômico).

Além disso, abordam que no âmbito da significação econômica, a palavra eficiência, além de ser relativa é objeto de disputa. Citando Roy (1997), as definições de eficiência dentro de um setor industrial, por exemplo, variam na história e conforme a orientação das diretorias: quando as diretrizes partem dos departamentos de produção, a eficiência é definida como custos de produção e crescentes outputs; quando o setor comercial é o mais forte, são os índices de vendas que definirão a eficiência; ou ainda, quando as decisões financeiras passam a dominar, serão os valores dos papéis da empresa no mercado de ações que irão definir o grau de eficiência do empreendimento.

No que se refere aos critérios utilizados para avaliar a eficiência, observa-se que se orientam apenas em termos da racionalidade do capital. Conforme advogam Parra (2002), Calbino e Paes de Paula (2014), os mesmos foram criados para permitir a comparação objetiva - do ponto de vista da ciência econômica - da eficiência entre diferentes organizações, tendo como parâmetro as condições técnicas e materiais de produção. Para os autores, tal instrumentalização já estava presente em Adam Smith e percorreu boa parte da história da ciência econômica. Citando Murphy (1993), afirmam que era preciso lidar com um problema prático: como medir e comparar a eficiência? Poder-se-ia imaginar critérios de qualidade e quantidade, valores de uso e possibilidades de reutilização dos produtos, satisfação dos consumidores, menores preços, maior durabilidade e tempo de trabalho.

Entretanto, no momento vivido por Adam Smith, qualquer índice associado à qualidade ou outra referência de origem moral, social ou cultural, deixaria de ser válido como medida, pois não serviria para o estabelecimento de critérios universais, mensuráveis e cientificamente legitimados. Assim, a rejeição do critério qualidade por Adam Smith ilustra a busca pelo conhecimento verificável, que não é baseado em tradições interpretativas particulares. Ou seja, a virada de Adam Smith para o quantitativo é motivada pela busca do conhecimento objetivo, que não esteja sujeito à moral, cultura ou à disputa política.

Poder-se-ia, no entanto, sob uma situação de similar condição institucional, por exemplo, comparar a eficiência produtiva de duas organizações distintas somente se os fins de ambos os processos analisados fossem os mesmos. Afinal, o critério do que é ser eficiente nunca é dado previamente dentro de um sistema complexo. É fundamental destacar que o que entra na contabilidade, enquanto input e output do cálculo de eficiência, será sempre o resultado de um permanente conflito político.

Por exemplo, o valor de uma hora trabalhada é sempre determinado pelo contexto social do trabalho e pelas lutas intrínsecas dos trabalhadores para obter 
benefícios, ou ainda, o valor dos insumos. Os custos ambientais, por sua vez, variam em função do que é ou não considerado uma externalidade econômica. Dessa forma, só se pode medir e comparar a eficiência de um determinado processo quando a escolha dos diferentes meios não influencia na definição do fim almejado, portanto, sem alterá-lo no decorrer do processo (PARRA, 2002).

Entretanto, ao mergulhar na complexidade do processo produtivo moderno, verifica-se que raramente a escolha dos meios não influencia nos fins, e ainda, é difícil haver consenso sobre os fins que devem ser alcançados, visto que eles normalmente trazem resultados diferentes para cada grupo social. Nessa perspectiva, tanto os fins como os meios do processo produtivo serão continuamente um campo de conflitos (PARRA, 2002; CORAGGIO, 2003; GAIGER, 2004; 2009; CALBINO; PAES DE PAULA, 2014). Por exemplo, a eficiência de determinada forma organizativa e tecnológica será também o resultado de um arranjo de forças sociais que combinam fatores técnicos (que conferem vantagens competitivas) com fatores sociais e políticos, que criam um ambiente econômico propício para tais técnicas. Como consequência, a eficiência surge como o reflexo de uma relação de poder que traduz uma capacidade de mobilizar recursos materiais e simbólicos a seu favor. Visto que, a relação entre os direitos, os títulos de propriedade e as responsabilidades dos indivíduos para com a produção e a distribuição da riqueza socialmente gerada, modificam-se na história.

Portanto, tornar-se eficiente implica em ações políticas, econômicas e sociais, uma vez que o Estado, principalmente, mas não só, é o responsável pela implementação, fiscalização e determinação das regras do desenvolvimento, como é também a arena onde se dará o combate pela definição. Isso permite dizer que o debate sobre a eficiência não pode estar dissociado das condições sociais e políticas que determinam e instituem os critérios que definem a mesma (PARRA, 2002; CORAGGIO, 2003; GAIGER, 2004; 2009; CALBINO; PAES DE PAULA, 2014).

\section{AS VISÕES RELATIVAS DA EFICIÊNCIA E AS DIMENSÕES QUE PERPASSAM O SEU CONCEITO}

Com uma posição semelhante às abordadas, Tauile e Debaco (2004) relatam que a compreensão da eficiência deve ir além da simples questão do lucro e dos retornos em curto prazo. Contextualizando o debate sobre a eficiência econômica, ressaltam que uma definição genérica seria que a eficiência é a capacidade de que agentes ou mecanismos têm de atingir seus objetivos e produzir os efeitos deles esperados, em função dos recursos utilizados. Em economia, o conceito ortodoxo, expresso pelo ótimo de Pareto, vê como eficiente uma condição na qual os agentes maximizam suas funções-objetivo. Segundo ele, é eficiente para a firma, maximizar o lucro ou minimizar os custos de produção e, para o consumidor, maximizar a satisfação ou minimizar as despesas. Esses conceitos, da forma como vêm sendo apresentados na teoria econômica, dependeria de funções-objetivo contínuas e bem comportadas.

No entanto, os autores discordam desta perspectiva utilitarista da eficiência econômica, afirmando que está além da lógica de se produzir mais em menos tempo, havendo que se considerar outras dimensões no âmbito social, cultural e formativo. A natureza e a atividade econômica nem sempre podem ser descritas de forma contínua, e questionam: o que se pode dizer a respeito da eficiência econômica e da satisfação dos consumidores quando o que está em jogo são recursos naturais não renováveis? 
Afirmam ainda que, mesmo as propostas decorrentes das análises ortodoxas que recomendam acrescentar um custo social para a poluição, sob a forma de uma taxa (BAUMOL; OATES, 1988), trazem problemas, pois qual seria a alíquota ótima de um imposto satisfatório para permitir que grandes empresas acabem com as reservas de água potável do mundo? Também há descontinuidade do bem-estar social, pela perda repentina de empregos decorrente do fechamento de uma fábrica, ou pela violência das grandes cidades, potencializada pelo desemprego, instabilidade e salários aviltantes (TAUILE; DEBACO, 2004; CALBINO; PAES DE PAULA, 2014).

Outro exemplo que utilizam para repensar a lógica da eficiência econômica, refere- se às organizações de recicladores de resíduos sólidos, que apresentam, do ponto de vista da eficiência econômica (ou seja, se interpretado como a relação entre insumo e produto), geralmente resultados que indicam uma baixa eficiência. Pois, na maioria das vezes o produto resultante do processo de coleta e triagem do lixo é muito inferior aos custos de produção, o que geralmente só se torna viável devido aos subsídios públicos, sob a forma de coleta e entrega dos resíduos nos galpões. No entanto, ressaltam que esta é uma política pública que tem aprovação praticamente unânime na sociedade. Além do plástico, do papel, do vidro e dos metais, essas organizações produzem emprego, renda, qualidade de vida, diminuição do volume de lixo em aterros sanitários, redução do desmatamento, reaproveitamento de recursos que demorariam séculos para serem biodegradados. Os benefícios sociais daí resultantes não são remunerados pelo mecanismo de mercado, especialmente quando se toma como referência o curto prazo.

Se eficiência diz respeito aos efeitos esperados, faz-se necessário encontrar uma forma de incluir não apenas mercadorias para a sociedade e lucro para os proprietários, mas postos de trabalho, qualidade de vida, preservação ambiental e valorização do ser humano (TAUILE; DEBACO, 2004; CALBINO; PAES DE PAULA, 2014). Conforme visto anteriormente, no contexto das organizações tradicionais, a concepção de eficiência pautada apenas pelos aspectos econômicos já é problemática, no caso das atividades de extensão em que tanto os meios quanto os fins, em tese, são diferentes, torna-se necessário repensar suas concepções.

Coraggio (2003) afirma que a eficiência pode ser chamada também de eficiência social. Para ele, os conceitos e valores associados à noção de eficiência diferem de acordo com cada contexto. No caso do capital, requer-se a combinação eficiente de ativos, força de trabalho, insumos e produtos que gerem a máxima taxa exagerada de lucro, no qual o crescimento quantitativo dos volumes de mercadorias é um critério definitivo da eficiência econômica. Neste sentido, ao fazer uma analogia do conceito do autor com as atividades de extensão, a lógica de eficiência, poderia por exemplo ser pautada pela qualidade de vida, pela realização efetiva do potencial das pessoas entrelaçadas por relações de solidariedade, com equidade. As questões econômicas e materiais, apesar de serem dotadas de significado, são um meio e não um fim, e o modo de estabelecer relações pessoais se baseia em processos mútuos de reconhecimento, negociação e acordo entre os pares. Assim, a eficiência social significa a busca pela reprodução das melhores condições possíveis, tanto materiais como simbólicas da vida em sociedade.

Já Gaiger (2004; 2009) faz uso do termo eficiência sistêmica, para ele o conceito de eficiência diz respeito, genericamente, ao grau de efetividade dos meios empregados em um dado processo para se alcançar um objetivo ou se gerar o resultado visado; em suma, concerne à relação entre meios e fins. Não obstante, quando se trata de processos sociais que mobilizam indivíduos e causam efeitos de profundidade e amplitude variáveis na sociedade, a análise da eficiência não pode 
abster-se de considerar a natureza dos fins buscados, o que descarta uma visão meramente instrumental do problema. Ademais, é necessário contabilizar tanto o dispêndio de recursos assumidos pelos indivíduos e pela organização diretamente implicada, quanto os custos indiretos, revertidos para a sociedade ou transferidos para gerações futuras (GAIGER, 2009). Por conseguinte, afirma que nos processos de produção econômica em particular, a eficiência deve ser entendida sob uma visão sistêmica e integrada às dimensões não econômicas. Ela compreende a capacidade de os processos e meios utilizados promoverem a qualidade de vida das pessoas que deles se valem, bem como propiciar maior bem-estar e segurança social. A eficiência neste contexto passa a compreender a materialização de benefícios sociais - e não meramente monetários ou econômicos -, a geração de efeitos benéficos ao entorno em que se situam as iniciativas em questão, a garantia de longevidade para estas e a concretização de externalidades positivas sobre o ambiente natural.

Assim considerada, a eficiência evoca uma racionalidade distinta, orientada à satisfação das necessidades e à realização das aspirações humanas, estimulando a simbiose com o ambiente natural, por meio de um vínculo integrador. Ela demanda outros estímulos para a ação, bem como um novo conjunto de indicadores para a avaliação e o direcionamento da atividade humana. Em síntese, a cadência de eficiência sistêmica deve ser tal que permita atingir os benefícios econômicos ou meramente monetários, mas também outros tipos de benefícios, como os sociais, a partir de uma conotação bem mais ampla, que se refere à qualidade de vida dos trabalhadores e à satisfação de objetivos culturais e ético-morais (GAIGER, 2004; CALBINO; PAES DE PAULA, 2014).

\section{METODOLOGIA}

Conforme abordado, o termo eficiência não está relacionado apenas uma dimensão conceitual, mas o mesmo pode apresentar uma pluralidade de perspectivas epistemológicas, o que torna o seu conceito amplo e abrangente. Com o intuito de abarcar o maior número possível de dimensões que se aproximam ou tentam criar fronteiras com a temática da eficiência nas atividades de extensão, foram selecionados trabalhos que fazem referência a este tema ou se aproximam desta discussão. Além disso, realizou-se um recorte temporal nas edições dos trabalhos analisados a partir do ano de 1987, data em que se conseguia obter acesso aos materiais eletrônicos, até o ano de 2015.

Os trabalhos investigados sobre a eficiência na extensão rural foram na Biblioteca Digital Brasileira de Teses e Dissertações e periódicos classificados nas categorias A1, A2, B1, B2, B3, B4 e B5 das áreas de Ciências agrárias. Recorrendo ao buscador do banco de dados, foram lançadas para a procura as palavras-chave: eficiência na extensão rural; eficiência nas atividades de extensão; extensão rural e eficiência. No lançamento da busca, o banco de dados apresentou a relação de trabalhos que referenciava no título, nas palavras-chave e/ou nos resumos o assunto procurado. Após a leitura dos resumos das dissertações e teses, foram encontrados apenas doze (12) dissertações que fazem referencia ao tema ou perpassam pelo mesmo. Quanto aos periódicos, foram encontrados apenas quatro (04) revistas brasileiras que continham artigos que abordam a temática eficiência na extensão rural, as mesmas foram revisadas desde suas primeiras edições até o ano de base de 2015, cuja investigação se realizou pela seleção prévia dos artigos baseados nos títulos e resumos que faziam menção à temática e estavam disponíveis online. Após a seleção, foram encontrados e classificados sete artigos em periódicos. 

categorias:

No que se refere aos critérios de análise, foram criadas as seguintes

a) Trabalhos publicados em dissertações/teses - buscou-se distinguir quais os trabalhos originaram de dissertações ou Teses.

b) Trabalhos publicados por periódico - nesta categoria foram apontados os trabalhos publicados por cada periódico.

c) Trabalhos publicados por ano - foi categorizada a evolução da produção da temática desde os primeiros anos até o período de 2015.

d) Natureza dos trabalhos - com base na categorização de Paes de Paula e Klechen (2007), foram divididos entre trabalhos teóricos, teórico-empíricos e empíricos. Por teóricos entendem-se aqueles que se limita a conceitos, proposições, construção e reconstrução de teorias e/ou modelos. Os trabalhos teórico-empíricos partem de um quadro de referências teóricas e buscam confirmá-lo ou refutá-lo através da análise dos dados. Já os trabalhos empíricos não apresentam um quadro de referências teóricas, relatando apenas as análises de dados e relatos de pesquisa.

e) Tipos de pesquisa - baseado na categorização de Godoi e Balsami (2004), foram divididos entre pesquisa qualitativa, quantitativa e qualitativa e quantitativa. Por pesquisa qualitativa entende-se a investigação cuja apresentação de dados e interpretações ocorre por meio de relatos, descrições e história de vida dos sujeitos e objetos investigados. Já a pesquisa quantitativa faz o uso estritamente de números para a apresentação e interpretação dos dados e informações. A pesquisa qualitativa e quantitativa utiliza ambos os recursos abordados anteriormente.

f) Temas de estudo - quanto aos temas verificaram-se quais os assuntos centrais abordados nos trabalhos, buscando identificar sobre qual vertente o termo eficiência foi abordado.

\section{RESULTADOS}

Após o levantamento e categorização dos dados, foram selecionados doze (12) trabalhos entre dissertações e sete (07) artigos em periódicos que perpassam sobre o tema "eficiência" aplicado à extensão. Quanto às teses, não foram encontrados trabalhos que discutissem à temática, uma possível justificativa seja o fato do programa de doutorado em extensão rural no Brasil ser relativamente novo, segundo Froehlich e Souza (2016) apenas em 2008 foi criada à primeira turma de doutorado no Brasil e América Latina, na Universidade Federal de Santa Maria.

Neste sentido, o primeiro resultado da pesquisa indica um baixo número de trabalhos publicados que discutam esta temática. Entre o período analisado de 1987 até 2015 , observou-se que houve apenas um pequeno aumento da produção nos últimos cinco anos (Tabela 1). 
Tabela 1 - Evolução da produção de trabalhos sobre a Eficiência na Extensão Rural

\begin{tabular}{crrr}
\hline Ano & Dissertações & Periódicos & \multicolumn{1}{c}{ Total } \\
\hline 1987 & 1 & 0 & 1 \\
2004 & 0 & 0 & 0 \\
2005 & 2 & 0 & 2 \\
2007 & 0 & 1 & 1 \\
2008 & 1 & 0 & 1 \\
2009 & 0 & 0 & 0 \\
2010 & 0 & 1 & 1 \\
2011 & 0 & 2 & 2 \\
2012 & 2 & 2 & 4 \\
2013 & 2 & 0 & 2 \\
2014 & 3 & 0 & 3 \\
2015 & 1 & 1 & 2 \\
\hline Total & $\mathbf{1 2}$ & $\mathbf{7}$ & $\mathbf{1 9}$ \\
\hline
\end{tabular}

Fonte: Elaborado pelos autores.

Quanto à produção de dissertações, ao apresentar os títulos dos trabalhos encontrados e uma análise dos mesmos, evidencia-se que a discussão da eficiência não é tratada como tema central, mas apenas fazendo menções à etimologia. Dentre as instituições, a Universidade Federal de Viçosa (UFV) apresenta-se com maior número de publicações em relação às demais. Uma hipótese, possivelmente seja pelo fato da instituição possuir um programa de pós-graduação consolidado na área de Extensão Rural (Quadro 1).

Quadro1 - Relação dos títulos de dissertações

\begin{tabular}{|c|c|c|}
\hline Títulos & Instituição & Ano \\
\hline $\begin{array}{l}\text { Transferência da informação tecnológica para produtores rurais: } \\
\text { estudo de caso no rio grande do norte }\end{array}$ & $\begin{array}{l}\text { Universidade Federal do } \\
\text { Rio de Janeiro (UFRJ) }\end{array}$ & 1987 \\
\hline $\begin{array}{l}\text { A Agroecologia e agricultura familiar da região centro-sul do } \\
\text { Paraná }\end{array}$ & $\begin{array}{l}\text { Universidade Federal do } \\
\text { Paraná (UFPR) }\end{array}$ & 2005 \\
\hline $\begin{array}{l}\text { Agricultura Urbana e Pobreza: Um Estudo no Município de } \\
\text { Santa Maria - RS }\end{array}$ & $\begin{array}{l}\text { Universidade Federal de } \\
\text { Santa Maria (UFSM) }\end{array}$ & 2005 \\
\hline $\begin{array}{l}\text { Extensão rural e floricultura tropical para o desenvolvimento } \\
\text { local: a cooperação no processo de inclusão competitiva dos } \\
\text { agricultores familiares em Pernambuco }\end{array}$ & $\begin{array}{l}\text { Universidade Federal } \\
\text { Rural de Pernambuco } \\
\text { (UFRPE) }\end{array}$ & 2008 \\
\hline $\begin{array}{l}\text { Assentamento Olga Benário: um estudo de caso da } \\
\text { espacialização da luta pela terra na zona da mata mineira }\end{array}$ & $\begin{array}{l}\text { Universidade Federal de } \\
\text { Viçosa (UFV) }\end{array}$ & 2012 \\
\hline $\begin{array}{l}\text { A web como instrumento de comunicação e extensão } \\
\text { universitária: um estudo de usuários do espaço do produtor }\end{array}$ & $\begin{array}{l}\text { Universidade Federal de } \\
\text { Viçosa (UFV) }\end{array}$ & 2012 \\
\hline $\begin{array}{l}\text { Caracterização da demanda de água em sistemas de irrigação } \\
\text { na bacia do córrego sossego em Itarana-ES. }\end{array}$ & $\begin{array}{l}\text { Universidade Federal de } \\
\text { Viçosa (UFV) }\end{array}$ & 2013 \\
\hline $\begin{array}{l}\text { Caracterização das atividades produtivas realizadas pelos } \\
\text { agricultores familiares do assentamento alecrim, em Selvíria- } \\
\text { MS. }\end{array}$ & $\begin{array}{l}\text { Universidade Estadual } \\
\text { Paulista (UNESP) }\end{array}$ & 2013 \\
\hline $\begin{array}{l}\text { A interiorização das universidades federais e os arranjos } \\
\text { produtivos locais: o caso da unidade acadêmica de Garanhuns } \\
\text { (UAG/UFRPE). }\end{array}$ & $\begin{array}{l}\text { Universidade Federal } \\
\text { Rural de Pernambuco } \\
\text { (UFRPE) }\end{array}$ & 2014 \\
\hline $\begin{array}{l}\text { Eficiência e difusão de tecnologia na produção de leite em minas } \\
\text { gerais }\end{array}$ & $\begin{array}{l}\text { Universidade Federal de } \\
\text { Viçosa (UFV) }\end{array}$ & 2014 \\
\hline $\begin{array}{l}\text { Fatores que afetam a inovação tecnológica de sistemas } \\
\text { produtivos de produtores familiares na cadeia produtiva leiteira } \\
\text { do distrito federal }\end{array}$ & $\begin{array}{l}\text { Universidade de Brasília } \\
\text { (UNB) }\end{array}$ & 2014 \\
\hline $\begin{array}{l}\text { O papel da assistência técnica e extensão rural na evolução dos } \\
\text { agroecossistemas familiares, fundamentados por práticas } \\
\text { agroecológicas na microrregião de Pato Branco - PR }\end{array}$ & $\begin{array}{l}\text { Universidade Federal } \\
\text { Rural de Pernambuco } \\
\text { (UFRPE) }\end{array}$ & 2014 \\
\hline
\end{tabular}

Fonte: elaborado pelos autores. 
Ao apresentar os trabalhos em periódicos e a análise dos mesmos, observa-se que diferente das dissertações, o termo eficiência é abordado na maioria dos títulos. No entanto, a discussão desta temática tampouco é o assunto central dos trabalhos (Quadro2).

Quadro2 - Relação dos títulos de artigos publicados em periódicos

\begin{tabular}{|l|l|c|}
\hline \multicolumn{1}{|c|}{ Títulos } & \multicolumn{1}{|c|}{ Instituição } & Ano \\
\hline $\begin{array}{l}\text { Plantio direto sem herbicidas: teste massivo e validação da } \\
\text { tecnologia por técnicos e agricultores familiares do estado } \\
\text { de santa Catarina }\end{array}$ & $\begin{array}{l}\text { Revista Brasileira de } \\
\text { Agroecologia (ABA) }\end{array}$ & 2007 \\
\hline $\begin{array}{l}\text { Eficiência de Metarhizium anisopliae (Metsch) Sorokin no } \\
\text { Controle de cigarrinhas-das-pastagens (Hemiptera: } \\
\text { Cercopidae) em Brachiaria bryzantha em Rondônia - Brasil }\end{array}$ & $\begin{array}{l}\text { Revista verde de } \\
\text { agroecologia e } \\
\text { desenvolvimento } \\
\text { sustentável (GVAA) }\end{array}$ & 2010 \\
\hline $\begin{array}{l}\text { A importância da extensão rural na formação de } \\
\text { inseminadores e na melhoria da eficiência reprodutiva em } \\
\text { Bovinos de leite }\end{array}$ & $\begin{array}{l}\text { Revista Extensão } \\
\text { Rural - Universidade } \\
\text { Federal de Santa } \\
\text { Maria (UFSM) }\end{array}$ & 2011 \\
\hline $\begin{array}{l}\text { Fatores associados à eficiência técnica e de escala das } \\
\text { cooperativas agropecuárias paranaenses }\end{array}$ & $\begin{array}{l}\text { Revista de Economia } \\
\text { e Sociologia Rural } \\
\text { (RESR) }\end{array}$ & 2011 \\
\hline $\begin{array}{l}\text { O cooperativismo e a gestão dos riscos de mercado: } \\
\text { análise da fronteira de eficiência do agronegócio } \\
\text { paranaense }\end{array}$ & $\begin{array}{l}\text { Revista de Economia } \\
\text { e Sociologia Rural } \\
\text { (RESR) }\end{array}$ & 2012 \\
\hline $\begin{array}{l}\text { Influência das Condições Ambientais e Ação Antrópica } \\
\text { Sobre a Eficiência Produtiva Agropecuária em Minas Gerais }\end{array}$ & $\begin{array}{l}\text { Revista de Economia } \\
\text { e Sociologia Rural } \\
\text { (RESR) }\end{array}$ & 2012 \\
\hline A Eficiência das Explorações Leiteiras Micaelenses & $\begin{array}{l}\text { Revista de Economia } \\
\text { e Sociologia Rural } \\
\text { (RESR) }\end{array}$ & 2015 \\
\hline
\end{tabular}

Fonte: Elaborado pelos autores.

No caso dos periódicos se observa que apenas quatro revistas na área de extensão rural foram encontrados trabalhos que perpassam pelo tema proposto. Nestes, as publicações se concentram nos extratos classificados de B1 e B3 respectivamente. Não se constatou trabalhos no extrato A1. Uma hipótese, no Brasil possui apenas três (03) programas de mestrado na área de Extensão Rural e apenas dois programas de doutorado, levando assim, ao baixo número de revistas nacionais nesta categoria. Além disso, as revistas classificadas no Extrato A1, não possuem um corpo editorial aberto para esta natureza de publicação (Tabela 2).

Tabela 2 - Relação do número de trabalhos em títulos de periódicos sobre a Eficiência na Extensão Rural

\begin{tabular}{|c|c|}
\hline $\begin{array}{l}\text { Extrato e título dos } \\
\text { periódicos }\end{array}$ & $\begin{array}{l}\text { Número de } \\
\text { trabalhos }\end{array}$ \\
\hline $\begin{array}{l}\text { B1 (RESR) } \\
\text { B3 (ABA) } \\
\text { B3 (Extensão Rural UFSM) } \\
\text { B5 (GVAA) }\end{array}$ & \\
\hline Total & 7 \\
\hline
\end{tabular}


Quanto à natureza dos trabalhos, foi possível observar distinções no que se refere à comparação entre dissertações e periódicos. Enquanto as publicações nos periódicos apresentavam-se entre trabalhos teóricos e/ou empíricos, as dissertações e teses predominaram por trabalhos de natureza teórico-empírico (Tabela 3).

Tabela 3 - Relação da natureza dos trabalhos e objeto de estudo sobre a Eficiência na Extensão Rural

\begin{tabular}{lrrrr}
\hline $\begin{array}{c}\text { Natureza dos } \\
\text { Trabalhos }\end{array}$ & $\begin{array}{c}\text { Número de trabalhos em } \\
\text { Dissertações / teses }\end{array}$ & $\begin{array}{c}\text { Número de trabalhos em } \\
\text { periódicos }\end{array}$ & \multicolumn{2}{c}{ Total } \\
\hline Teórico-Empírico & 11 & 1 & 12 \\
Teérico & 1 & 3 & 4 \\
Empírico & 0 & 3 & 3 \\
\hline
\end{tabular}

Fonte: Elaborado pelos autores.

Vinculado às naturezas dos trabalhos, buscou-se compreender quais os tipos de pesquisa foram utilizadas. Observou-se que foi majoritária a predominância da pesquisa quantitativa dentre os periódicos. Em contrapartida, nas dissertações houve uma predominância pelo método qualitativo (Tabela 4).

Tabela 4 - Relação dos tipos de pesquisa sobre a Eficiência na Extensão Rural

\begin{tabular}{lrrrr}
\hline $\begin{array}{c}\text { Método de } \\
\text { pesquisa }\end{array}$ & $\begin{array}{c}\text { Número de trabalhos em } \\
\text { Dissertações }\end{array}$ & $\begin{array}{c}\text { Número de trabalhos em } \\
\text { periódicos }\end{array}$ & Total \\
\hline Qualitativo & 6 & 0 & 6 \\
Quantitativo & 3 & 6 & 9 \\
Quantitativo- & 3 & 1 & 4 \\
Qualitativo & & & 1 & \\
\hline
\end{tabular}

Fonte: Elaborado pelos autores.

Por fim, quanto aos conceitos vinculados a eficiência nos trabalhos analisados, é possível inferir que os mesmos não trazem como eixo central de discussão à eficiência na extensão rural, mas perpassam por este tema abordando uma visão tradicional da mesma, sem fazer referência a uma relativização do termo.

As discussões trazem questões principalmente relacionadas à produtividade do campo, analise comercial e técnica da produção agronômica. Em contraponto, um trabalho que faz uma rica crítica a visão tradicional de eficiência é apresentada nos trechos do estudo de Zuin et al. (2011), ao relatar um exemplo empírico de como muitas vezes, ocorre o processo de transferência de tecnologia aos produtores a partir de reuniões.

Foi solicitado aos entrevistados um exemplo de como era realizada a condução dos encontros. Os extensionistas fizeram um relato de uma reunião, cuja temática se circunscrevia à reprodução de gados. Inicialmente, o extensionista abordava as pendências das reuniões passadas e depois iria ao foco do tema relativo ao encontro, como, por exemplo, produtos hormonais a serem empregados em bovinos. $O$ primeiro passo da reunião foi o relato da importância do produto e técnica aos agricultores, visando persuadi-los a adotar a técnica ofertada Perguntou-se como ocorria o processo de convencimento e a essa indagação os extensionistas responderam que "sempre se convence um produtor a partir do bolso dele. Mostra-se o tempo em que eles estão perdendo de não se fazer algo". 
Realizada a introdução da temática pelo extensionista é agendada a visita de um palestrante (geralmente de uma empresa de insumos) para expor novamente sobre o tema aos agricultores, reforçando o processo de persuasão da técnica para os agricultores, atitude que busca validar a tecnologia junto aos possíveis consumidores. Ao final da reunião, são agendadas visitas para o grupo de produtores convencidos da importância de se adotar a tecnologia demonstrada. Foi indagado se essa metodologia de ensino-aprendizado era participativa. Basicamente, os entrevistados repetiram aquilo que já haviam enunciado, deixando claro que a prática continua sendo tradicional, expositiva e hierárquica (ZUIN et al., 2011).

Zuin et al. (2011) também investigou a reação dos produtores diante das reuniões para transferência de tecnologia, pelo qual os mesmos fazem uma leitura pessoal destas reuniões a partir de sua concepção e entendimento.

Durante os questionamentos, perguntamos se os produtores dialogavam com os extensionistas nesses encontros. A resposta foi que "os produtores falam o que pensam, mas você tem que ficar esperto para não mudar o foco. Eles começam a falar do particular. Você tem que entrar como mediador interrompendo o devaneio". Com essa enunciação, percebemos que o extensionista perde uma oportunidade ímpar enquanto educador, uma vez que, quando os agricultores começam a falar, eles estão produzindo sentidos, tentando entender os significados sociais que transmitem os extensionistas a partir da sua leitura de mundo (ZUIN et al., 2011).

Em outra vertente do conceito de eficiência, porém também crítica à visão tradicional, Firmino (2014) em sua dissertação aborda a concepção de extensão rural sendo aplicada pela Universidade Federal da unidade acadêmica de Garanhuns (UAG/UFRPE).

De acordo com os professores participantes da pesquisa, particularmente aqueles que apresentam somente atividades de pesquisa, a divulgação dos resultados de suas pesquisas são publicadas em periódicos científicos, eventos, revistas científicas. Este procedimento acaba dificultando a disseminação do conhecimento, pois restringe o acesso àqueles que não têm ciência desse mecanismo. Sendo assim, os conhecimentos o qual a Universidade é detentora não são totalmente repassados, socializados diretamente aos atores do arranjo do produto local. Os produtores e laticínios assumiram que as pesquisas por parte da UAG/UFRPE, apesar de serem importantes, não atendem suas expectativas, em razão de não terem conhecimento dos resultados (FIRMINO, 2014).

Observa-se que à crítica do autor a presente eficiência se vincula exclusivamente ao resultado acadêmico gerado. Quanto aos produtores, a abordagem na busca de dados para gerar pesquisa sem um retorno aos mesmos traz insatisfação, e conforme Firmino (2014), os produtores concluem que este tipo de extensão chega a ser desnecessária pelo fato dos resultados não chegar até eles. 
Já Bezerra et al. (2011) aponta em seu trabalho questões de autoanálise para os extensionistas em suas atividades de campo, na qual o mesmo pode ser utilizado para se pensar à forma como tem sido aplicada à extensão:

\begin{abstract}
É pensando de forma crítica a prática de hoje que se pode melhorar a prática de amanhã, auxiliando a encontrar respostas para questões como: a forma utilizada, atualmente, na formação de inseminadores através dos projetos de extensão está atendendo as necessidades e anseios dos produtores de leite? Até que ponto a técnica apreendida está sendo aplicada de forma correta nas propriedades? Estão ocorrendo melhorias nos índices de prenhez dos animais, bem como diminuição dos custos/prenhez e avanços no padrão genético dos animais? (BEZERRA et al., 2011).
\end{abstract}

As questões geradas por Bezerra et al. (2011) inferem uma preocupação quanto ao respaldo dos produtores na utilização das técnicas que lhe são ofertadas. Apesar da eficiência se vincular ao desenvolvimento do saber técnico gerado, há uma preocupação por parte do extensionista em saber se estas práticas têm sido aplicadas de forma correta ou não, se as mesmas têm chegado até os produtores.

No âmbito da discussão da eficiência, observa-se que a mesma perpassa mais por questões da utilização correta ou não das técnicas ofertadas e o resultado produtivo e econômico gerado. Ainda que seja importante esta discussão, não há uma relativização do conceito de eficiência, bem como, os objetivos e visões dos produtores não são discutidos.

Neste ínterim, ao realizar atividades de extensão que envolve não apenas um produtor, mas uma comunidade na lógica de um assentamento, Teixeira (2012) em sua dissertação aborda que o trabalho extensionista para ser eficiente necessita também da alocação de recursos de políticas públicas para garantir ao assentamento o acesso ao auxilio técnico da extensão nas áreas econômica, produtiva, social e de direitos básicos de moradia:

Nesse sentido percebe-se uma frustração por parte do assentado em relação a ter um lote de terra e não ter os recursos financeiros e assessoria técnica para fazê-la produzir e gerar renda. A expectativa do acesso ao lote de terra como fator de melhorias de sua condição de vida ainda não foi idealizado (TEIXEIRA, 2012).

Para que todos estes fatores possam interagir, é preciso que o Governo assuma a sua responsabilidade e conduza esta relevante política pública nos moldes democráticos, procurando buscar o desenvolvimento dos projetos de assentamentos dentro de uma realidade onde as famílias com suas singularidades possam conviver em harmonia e realizar seus diferentes objetivos, melhorando as suas condições de vida (TEIXEIRA, 2012).

Ainda sobre a lógica de assentamento, Laluce (2013) em sua dissertação amplia o conceito de eficiência para a sua dimensão social, enfatizando que na dinâmica de um assentamento, é relevante a valorização de outras dimensões da vida e do trabalho.

A grande maioria das famílias vê como fatores que dificultam o desenvolvimento do Assentamento as disputas políticas, a falta de união dos produtores e os entraves relacionados à comercialização. Isso a nosso ver é um reflexo do baixo capital 
social do Assentamento, principalmente devido à falta de espaços de convívio entre as famílias e os colaboradores do processo de desenvolvimento do Assentamento, pois nestes espaços muitas diferenças poderiam ser resolvidas e os laços sociais estreitados, facilitando a problematização da realidade e a busca de soluções (LALUCE, 2013).

Conforme aborda o autor, a eficiência na solução de problemas econômicos e sociais não esta relacionado apenas ao conhecimento técnico na solução de problemas, mas devido à falta de convívio social e dialogo entre os assentados.

Apesar da baixa produção na maioria dos lotes, outros aspectos do dia a dia das famílias têm demonstrado que a reprodução da vida nestes territórios não está na dependência direta somente da eficiência dos sistemas produtivos (LALUCE, 2013).

Observa-se na revisão da literatura que alguns trabalhos, ainda que não tratassem diretamente da etimologia eficiência e tampouco tratassem do seu conceito em uma perspectiva não neutra e histórica, deram alguns indícios da ampliação do seu conceito. Apesar destas exceções, os demais estudos partiam de uma visão majoritariamente das dimensões técnicas, produtivistas e econômicas da eficiência, naturalizando seu construto social.

Uma hipótese do quadro atual, talvez possa ser explicada pelo histórico da visão difusionista tecnológica na qual a extensão rural no Brasil sofreu influencia desde o seu período de implantação. Na ocasião, vinculava-se as suas ações a uma modernização e expansão do campo, buscando-se principalmente 0 desenvolvimento e crescimento técnico/econômico.

\section{APONTAMENTOS PARA UM CONSTRUTO TEÓRICO DE EFICIÊNCIA NA EXTENSÃO RURAL}

Com o objetivo central de discutir o conceito de eficiência nas atividades de extensão rural, o trabalho teórico-empírico sustentou a relativização do termo, considerando que o mesmo possui outras dimensões de eficiência além das que são corriqueiramente utilizadas.

Em uma análise da literatura, constatou-se que a mesma trata o termo eficiência vinculada majoritariamente às questões técnicas e produtivas ${ }^{3}$. Neste ínterim, e ampliando a visão da extensão para a área, propõe-se um construto teórico, exemplificando que ser eficiente nas práticas extensionistas está além da visão tradicional de aumentar a receita e ou eficiência técnica de um processo. Trazendo como base a premissa de que a extensão rural serve ao produtor buscando adequar-se à realidade e objetivos propostos pelo mesmo, a definição por eficiência visa um acordo com a realidade e os objetivos almejados, de forma coerente com a real vivencia de cada comunidade.

Neste sentido, o construto teórico propõe incorporar outros aspectos que ainda não plenamente discutidos na literatura, conforme na figura 1.

\footnotetext{
${ }^{3}$ Apesar da extensa revisão da literatura realizada no presente trabalho, contudo, é relevante ressaltar que enquanto limitações o estudo realizou as buscas utilizando exclusivamente a etimologia eficiência. De modo, ao não abarcar temas correlatos, é possível que outras etimologias que talvez pudessem ampliar a discussão, não foram contemplados.
} 
Figura 1 - Dimensões da eficiência na Extensão Rural

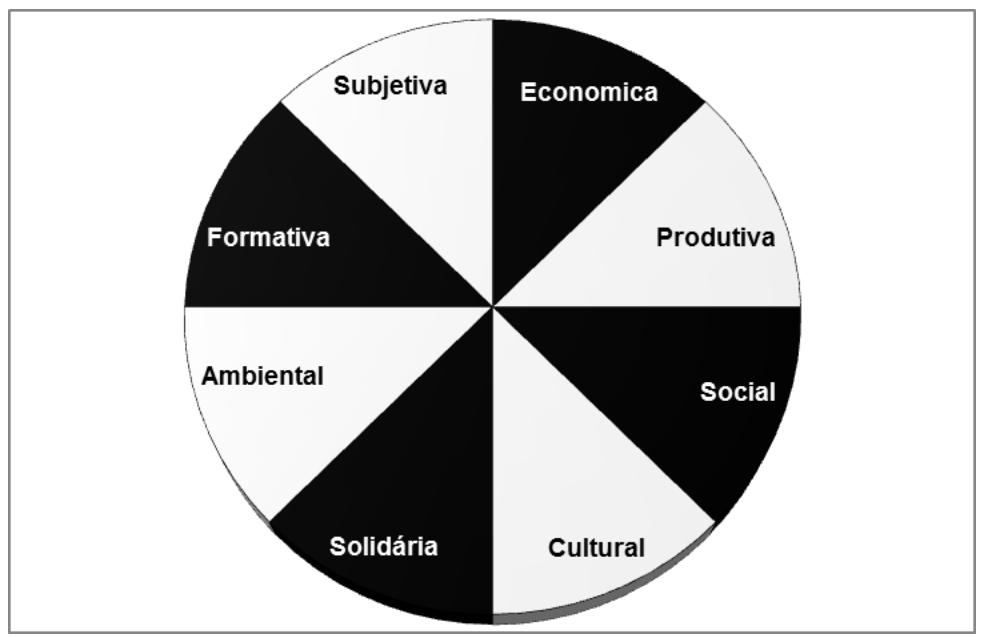

Fonte: Elaborado pelos autores.

\section{Construto teórico - Dimensões da Eficiência}

- Dimensão social - A eficiência pode ser vista como o fortalecimento das relações entre os sujeitos, estabelecendo confiança e garantindo um retorno nas relações interpessoais.

- Dimensão cultural - É a transformação na qual o sujeito pode desconstruir os valores assistencialistas, patriarcais de dependência e subordinação. A eficiência cultural cria oportunidades para este desenvolvimento, resultando em autonomia e autoconfiança dos sujeitos.

- $\quad$ Dimensão solidária - Quando se trabalha em um processo de intervenção social pode-se fomentar a solidariedade entre os sujeitos, aumentando a cooperação no desenvolvimento dos trabalhos e, em via de consequência, a confiança e comunicação entre os envolvidos.

- $\quad$ Dimensão ambiental - A eficiência neste campo prioriza a preservação dos recursos naturais e a prática de atividades ecologicamente corretas.

- Dimensão Formativa - apresentam-se no desenvolvimento das práticas extensionistas, gerando aprendizado ao elevar o conhecimento sobre os aspectos técnicos de produção, financeiro, econômico e político.

- Dimensão Subjetiva - Trata-se dos retornos gerados pelas melhorias na autoestima dos sujeitos envolvidos, nos sentimentos de identidades e pertencimentos com as comunidades locais, e nas projeções de vida.

Assim, pensar em eficiência pode envolver outras dimensões apresentadas, onde é possível desconstruir a visão tradicional e neutra, de que ser eficiente é alcançar apenas os objetivos técnicos, produtivos e econômicos no campo. Nota-se com o construto acima que, se durante um trabalho do extensionista os retornos técnicos e econômicos, como o aumento da produtividade dos produtores rurais não foram atingidos, porém, se a intervenção gerou outras formas de aprendizado nos produtores, aumentou a autoestima, contribuiu para o fortalecimento da associação local, não se pode dizer que não se alcançou a eficiência, mas que esta se expandiu para outros resultados não econômicos. Da mesma forma, uma intervenção que 
gera significativos retornos econômicos para os produtores, porém ao custo da degradação ambiental, da fragmentação social entre os envolvidos, também deve ser relativizada quando ao seu próprio êxito.

Em conclusão, espera-se que o presente construto sirva de base para demonstrar a amplitude que o campo de extensão rural pode alcançar ao se tratar da eficiência, compreendendo, que a dimensão econômica e técnica são importantes, mas também deve-se considerar outras lógicas como a social, ambiental, cultural, envolvidas nos objetivos e necessidades de cada produtor.

\section{REFERÊNCIAS}

ALMEIDA, B. A. S.; SILVA, E. L. D. G. S. A Eficiência das explorações leiteiras micaelenses (Açores). Revista de Economia e Sociologia Rural [online]. 2015, v. 53, suppl.1, p.129-142.

BAUMOL, W. J.; OATES, W. E. The theory of environmental policy. Cambridge: Cambridge University, 1988.

BEZERRA, E. S.; SANCHEZ, S. B; ULRICH, V. R. A importância da extensão rural na formação de Inseminadores e na melhoria da eficiência reprodutiva em Bovinos de leite. Extensão Rural, Santa Maria, Ano XVIII, n. 21, jan./jun. 2011. Disponível em: <https://periodicos.ufsm.br/extensaorural/article/view/5572/3293>. Acesso em: 15 set. 2017.

BORTOLOTTI, M. A. O papel da assistência técnica e extensão rural na evolução dos agroecossistemas familiares, fundamentados por práticas agroecológicas na microrregião de Pato Branco - PR. 2014. 81f. Dissertação (Mestrado em Desenvolvimento Regional) - Universidade Tecnológica Federal do Paraná, Pato Branco, 2014.

BRASIL, Ministério do desenvolvimento agrário. Política Nacional de Assistência Técnica e Extensão Rural. Brasília, 2007.

CALBINO, D.; PAES DE PAULA, A. P. A mitologia da ineficiência nas organizações solidárias: em busca da ressignificação do conceito. Desenvolvimento em Questão, v.12, n. 27, p. 42-65, 2014.

CAMPOS, S. A. C; COELHO, A. B; GOMES, A.P. Influência das condições ambientais e ação antrópica sobre produtiva agropecuária para a eficiência em Minas Gerais. Jornal de Economia e Sociologia Rural, v. 50, n. 3, p. 563-576, 2012.

CAPORAL, F. R.; COSTABEBER, J. A. Agroecologia e extensão rural: Contribuições para a promoção do desenvolvimento rural sustentável. Brasília: MDA/SAF/DATER - IICA, 2004.

CORAGGIO, J. Economia del trabajo. In: CATTANI, A (org.), La otra economia. Porto Alegre: Veraz, 2003, p.88-95.

DARÉ, J. C. Caracterização da demanda de água em sistemas de irrigação na bacia do córrego sossego em Itarana - ES. 2013. 73f. Dissertação (Mestrado em Engenharia Agrícola) - Universidade Federal de Viçosa, Viçosa, MG, 2013. 
ERVILHA, G. T. Eficiência e difusão de tecnologia na produção de leite em Minas gerais. 2014. 83 f. Dissertação (Mestrado em Economia) - Universidade Federal de Viçosa, Viçosa, MG, 2014.

FIRMINO, A. L. S. A interiorização das Universidades Federais e os arranjos produtivos locais: o caso da unidade acadêmica de Garanhuns (UAG/UFRPE). 2014. 119f. Dissertação (Mestrado em Administração e Desenvolvimento Rural) Universidade Federal Rural de Pernambuco, Recife, 2014.

FREIRE, I.M. Transferência da informação tecnológica para produtores rurais: estudo de caso no Rio Grande do Norte. 1987. Dissertação (Mestrado em Ciência da informação) - Instituto brasileiro de Informação em Ciência e Tecnologia, Rio de Janeiro. 1987.

FROEHLICH, J. M.; SOUZA, R. S. Pós-graduação em extensão rural da UFSM: 40 anos e além...! Extensão Rural, Santa Maria, v. 23, n. 3, jul./set 2016. Disponível em: <https://periodicos.ufsm.br/extensaorural/article/view/24452/pdf>. Acesso em: 15 set. 2017.

GAIGER, L. I. Eiciência sistêmica. In: CATTANI; A; LAVILLE, L; GAIGER, L. (orgs.). Dicionário internacioal da outra economia. Coimbra: Almedina, 2009, p. 169-175.

GODOI, C. K.; BALSINI, C. P. V. A Metodologia qualitativa nos estudos organizacionais: análise da produção científica brasileira entre 1997 e 2003. In: III ENEOS. Anais... Atibaia, 2004.

LALUCE, C. R. H. Caracterização das atividades produtivas realizadas pelos agricultores familiares do Assentamento Alecrim, em Selvíria-MS. 2013. 100f. Dissertação (mestrado em Agronomia. Especialidade: Sistemas de Produção.) Universidade Estadual Paulista. Faculdade de Engenharia de Ilha Solteira, São Paulo, 2013.

LANA, M. A. et al. Plantio direto sem herbicidas: teste massivo e validação da tecnologia por técnicos e agricultores familiares do estado de Santa Catarina. Revista Brasileira de Agroecologia, [S.I.], v. 2, n. 2, set. 2007. Disponível em: <http://www.abaagroecologia.org.br/revistas/index.php/rbagroecologia/article/view/72 94>. Acesso em: 14 Nov. 2016.

LUZ, C. C. V. Fatores que afetam a inovação tecnológica de sistemas produtivos de produtores familiares na cadeia produtiva leiteira do Distrito Federal. 2014. 192 f. Dissertação (Mestrado em Agronegócio) - Faculdade de Agronomia e Medicina Veterinária, Universidade de Brasília, Brasília, 2014.

MOREIRA, V. R.; SILVA, C. L.; MORAES, E. A.; PROTIL, R. M. O cooperativismo e a gestão dos riscos de mercado: análise da fronteira de eficiência do agronegócio paranaense. Revista de Economia e Sociologia Rural [online]. 2012, v.50, n. 1, p.51-68. Jan./Mar. 2012.

MOTA, J. B. A web como instrumento de comunicação e extensão universitária: um estudo de usuários do espaço do produtor. 2012. 121f. Dissertação (Mestrado em Extensão Rural) - Universidade Federal de Viçosa, Viçosa, MG, 2012. 
MURPHY, J. The moral economy of labor: aristotelian themes in economy theory. Yale: Yale University Press, 1993.

PAES DE PAULA, A. P.; KLECHEN, C. F. A tradição autônoma dos estudos críticos em administração no Brasil: um estudo da produção científica de 1980 a 2004. In: XXXI ENANPAD. Anais... Rio de Janeiro, 2007.

PARRA, $\mathrm{H}$. Liberdade e necessidade: Empresas de trabalhadores autogeridos e a construção sócio-político da economia (Mestrado em...). Universidade Federal de São Paulo, São Paulo, Brasil, 2002.

QUADROS, K. R. A agroecologia e agricultura familiar da região Centro-Sul do Paraná. 2005. 114 f. Dissertação (Mestrado em Agronomia - Produção Vegetal) Universidade Federal do Paraná, Curitiba. 2005.

ROY, W. Socializing capital: the rise of the large industrial corporation in America. New Jersey: Princeton University Press, 1997.

SIVA, F. C. Extensão rural e floricultura tropical para o desenvolvimento local: A cooperação no processo de inclusão competitiva dos agricultores familiares em Pernambuco. 2008. 144f. Dissertação (Mestrado em Extensão Rural e Desenvolvimento Local) Universidade Federal Rural de Pernambuco, Recife, 2008.

SOUZA, U. R.; BRAGA, M. J.; FERREIRA, M. A. M. Fatores associados à eficiência técnica e de escala das cooperativas agropecuárias paranaenses. Revista de Economia e Sociologia Rural, Piracicaba, SP, v. 49, n. 3, p. 573-598, jul./set. 2011.

TAUILE, J.; DEBACO, E. Autogestão no Brasil: o salto de qualidade nas políticas públicas. Indicadores Econômicos, Revista Indicadores Econômicos FEE, v.32, n.1, p.197-220, 2004.

TEIXEIRA, M. T. Assentamento Olga Benário: Um estudo de caso da espacialização da luta pela terra na zona da mata mineira. 2012. $129 f$ Dissertação (mestrado em Extensão Rural) - Universidade Federal de Viçosa, Viçosa, MG, 2012.

TEIXEIRA, V. M.; SÁ, L. A. N. Eficiência de Metarhizium anisopliae (Metsch) Sorokin no Controle de cigarrinhas-das-pastagens (Hemiptera: Cercopidae) em Brachiaria bryzantha em Rondônia - Brasil. Revista Verde, v. 5, n. 3, p. 263 - 273, 2010.

ZUIN, L. et al. A comunicação dialógica como fator determinante para os processos de ensino-aprendizagem que ocorrem na capacitação rural: um estudo de caso em um órgão público de extensão localizado no interior do Estado de São Paulo. Ciência Rural, v. 41, n. 5, p. 917-923, 2011. 